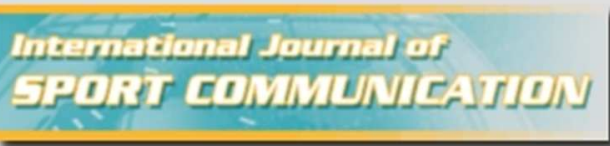

\title{
Evaluating Broadcast Strategy: the Case of Australian
} Football

\begin{tabular}{|r|l|}
\hline Journal: & International Journal of Sport Communication \\
\hline Manuscript ID: & IJSC.2015-0063 \\
\hline Manuscript Type: & Articles \\
\hline Keywords: & Sport Broadcasting, Television, Strategy, Football \\
\hline \multicolumn{3}{c}{} \\
\multicolumn{3}{c}{ SCHOLARONE } \\
\\
\multicolumn{3}{c}{ Manuscripts } \\
\end{tabular}




\section{Introduction}

The dramatic growth in broadcast rights paid by media corporations over the past three decades has seen once 'small-time' sport organisations grow into multi-billion dollar enterprises (Rowe, 1996). With the ever increasing availability of broadcast technologies over this time-frame, broadcast rights for popular sports and events, such as the Olympic Games and the Football World Cup, have made sports broadcasting a critical feature for global media institutions (Frawley \& Adair, 2013). Given this continued development, there has been growing importance for sport management researchers to understand the drivers of broadcast rights and their valuations, to provide greater knowledge into how media broadcast strategy is formed (Gratton \& Solberg, 2007).

Developing a well-defined and effective broadcast strategy is particularly critical to National Sporting Organisations (NSOs) that operate in very competitive sport markets. One such competitive market is Australia, which has four distinct football codes all vying for market share with other sports. Competition for television coverage is particularly fierce in the Australian market place given there is a small pool of broadcasters. The Australian freeto-air (FTA) television market consists of five networks: three commercially managed networks and two publicly owned stations that have historically not paid for commercial sports rights. Furthermore, Australia has just one pay television provider (Foxtel) which holds a modest market penetration rate of approximately 30\% (OzTAM, 2013).

While sport content is a cornerstone within the Foxtel platform offer, consistently accounting for over ninety of the top one hundred highest rating programs annually (Consolidated Media Holdings, 2011), it does so within staunch anti-siphoning restraints. Australian anti-siphoning legislation enshrines key sport events such as the Australian Football League (AFL) and National Rugby League (NRL) Grand Finals, the Olympic Games, and major tennis and golf tournaments continue to be shown on FTA television 
(Nicholson, 2007). However, despite such regulations, only a small number of sports generate regular coverage beyond what is mandated and fewer have the capability to demand significant broadcast rights fees for their content (Fujak \& Frawley, 2014). This article is concerned with comparing the broadcast strategy of the two largest commercial sports in the Australian marketplace, the biggest being the AFL and the second biggest, the NRL (Fujak, 2012). Due to their ratings and commercial power, these two sports represent a small number of sports that can achieve large rights fees as well as command their own broadcast strategy agenda in the Australian media market.

The central objective of the paper, therefore, is to evaluate the broadcast structure of the AFL and NRL through a quantitative analysis of their television ratings during the period 2007 to 2011. Specifically, the research is focused on quantifying the structural components of each league's broadcast agreements to assess the alignment with league objectives. The structural components of the television deals are evaluated within the team sport broadcasting principles established by Noll (2007). Therefore, the study endeavours to address three central research questions:

RQ1: How do the AFL and NRL broadcast structures differ?

RQ2: What are the implications of broadcast structures on league stakeholders?

RQ3: Do these broadcast structures align with stated strategic objectives of each league?

To achieve this outcome the paper is presented in four parts. The first part discusses the sport broadcasting literature. This is followed by an explanation of the adopted research methodology. The third part presents the data analysis and discussion. The fourth and final part concludes the paper outlining ideas and issues for future research. 


\section{Literature Review}

\section{Sport Broadcasting}

The field of sport economics has received considerable attention over the past half century, driven by the 'peculiar' nature of demand-side markets for professional sporting competitions (Neale, 1964). In more recent years, interest in the field has been fuelled by the increasing economic significance of professional sports for a variety of stakeholders (Borland \& Macdonald, 2003). Traditional methods of sport funding, such as member contributions, have given way to gate receipts and sponsorship, which themselves are now losing dominance to broadcast rights and intellectual property rights as key revenue drivers (Andreff \& Staudohar, 2000). While this continually developing model of sport funding has created robust debate regarding the nature of sport for its stakeholders, it is surprising that despite becoming the dominant source of income for most elite professional sporting competitions (Stewart \& Smith, 2000), there has been relatively little discussion regarding the real-world application of sport broadcasting and strategy in commercial settings, particularly in an Australian context (Borland \& Macdonald, 2003).

Existing conceptual and practical evidence indicates that sports rights are of high value to broadcasters. For instance, Macdonald and Booth's (2007) examination of football in Australia identifies the extensive position of sport in the national broadcast landscape. Notably, sport content not only generates improved advertising revenue and subscriber rates via its appeal among lucrative demographics, it can also provide positive spill-over effects for a broadcaster's brand and other programming (Hoehn \& Lancefield, 2003). Additionally, the commitment of sports fans to their team and sport provides broadcasters with a loyal audience in an era where new technologies and media platforms are exacerbating audience fragmentation (Szymanski, 2006). It is noteworthy, however, that the value derived from 
sport broadcasts differs between FTA and subscription platforms. As observed by Noll (2007) with television channels that charge for viewing, income from viewers is added to advertising revenues to establish the value of the program. For sport content to be of a higher value to a pay-TV network than a FTA channel, a portion of viewers will be happy to pay the cost to watch instead of not paying anything to watch other programs. As increasing prices diminishes the quantity sold, establishing the price for watching content above zero decreases the overall number of viewers and therefore the amount of advertising that can be generated. A pay-TV network in this instance will pay more for sports than a FTA channel if the additional revenue gained from the viewer subscription is offset by the reduction in advertising revenues (Noll, 2007).

The value of sport content is reflected in the growth of financial valuations. From an initial broadcast agreement valued at $£ 60.8$ million per season in 1992, the English Premier League's (EPL) most recent agreement includes remuneration of $£ 1.7$ billion per season, for the 2016-2017 season onwards (BBC, 2015). Similar growth has occurred in the Australian market. Expenditure by FTA broadcasters on sport content rose from A $\$ 92.6$ million in 1990/91 to A $\$ 225.8$ million in 2004/05, with the major sporting leagues the main beneficiaries (Macdonald \& Booth, 2007). This can be evidenced using the Australian Football League (AFL), whose most recent agreement was valued at A $\$ 250$ million per season, a considerable increase on the A\$6 million generated per season in its 1988-1992 agreement (Fujak, 2012; Fujak \& Frawley, 2013). Furthermore, it has been speculated that both the AFL and NRL will be able to achieve further significant rights growth of approximately $\mathrm{A} \$ 400$ to $\mathrm{A} \$ 500$ million in their next contract negotiations (Masters, 2015).

Notwithstanding the dramatic increase in broadcast valuations it has been noted: "there has been little research undertaken into the breadth of delivery and significance of broadcast coverage" (Turner \& Shilbury, 2005, p. 167). The paucity of research may in fact 
be due to the lack of access to broadcast ratings data rather than intent (Fujak, 2012; Fujak \& Frawley, 2013). For example, Stewart and Dickson (2007) argued that the AFL sought to ensure quality broadcast coverage in the northern Australian states but were unable to support their analysis with any significant broadcast ratings data. Furthermore, Rowe and Gilmour (2009) identify the near-exclusive coverage of football (soccer) in Australia on a subscription medium as "running the risk of limiting its audience reach and, therefore, of retarding its development" (p. 16). Yet little quantitative evidence is provided to support the evaluation of the implemented broadcast strategy. Their findings however support that of Turner and Shilbury (2005), who in a qualitative analysis of the views of 21 senior sport managers, found the consensus that FTA coverage was paramount in order to achieve league and club sustainability. Turner and Shilbury's (1997) analysis of AFL broadcasts however is one of the few studies that utilised broadcast ratings data in the Australian sporting context. They were able to access the now defunct Nielson television ratings data-set for a sample of AFL matches played during the 1995 season. The study found that the investment by Channel Seven in broadcasting AFL resulted in a strong return for the broadcaster and advertisers.

While the analysis of quantitative sport broadcasting data in Australia has been relatively limited, the international experience is more advanced (Fujak \& Frawley, 2013). The growth of the international research has been focused in Europe and North America where a number of studies have accessed detailed broadcast ratings data (Solberg \& Hammervold, 2008; Tainsky, 2010). However, the emphasis of this recent research has generally focused on quantitative modelling of broadcast demand, with corresponding strategic implications of results often underdeveloped. Johnsen and Solvoll (2007), for instance, examined Norwegian football audiences to explore the impact of football-specific and television-specific factors on demand for public and subscription television. The study found that demand on viewership for public service broadcasters was impacted by scheduling 
and related variables such as broadcast time of day and the day of week, rather than footballspecific factors like match quality or the uncertainty of match outcome. In contrast, subscription viewers were less responsive to scheduling factors and more sensitive to football-specific considerations.

In similar studies, Feddersen and Rott (2011), concluded that star players and the opposition quality were of greater importance than non-match variables such as the start time and weather conditions. Earlier work by Hammervold and Solberg (2006) found there was a preference for finals broadcasts as opposed to regular season matches among Norwegian football followers. Another study by Forrest et al. (2005) into the impact of match outcome uncertainty on broadcast demand for EPL, found that the three of the biggest EPL clubs (Liverpool, Arsenal and Manchester United) drew larger broadcast ratings, over and above the other control variables such as day of the week and time of kick-off. This finding suggested that broadcasting revenues could be maximised when broadcasters were able to choose matches without contract related game selection constraints. Furthermore, the work of Forrest et al. (2004) found that the policy of limiting live EPL games between 1992 and 2001 was a poor broadcast strategy resulting in sub-optimal outcomes for the league and broadcasters. Yet while studies like those mentioned above have started to consider the underlying strategic themes that shape the sport broadcasting environment in Europe and North America, very little empirical work has focused on evaluating sport broadcast strategy in an Australian context. The aim of this paper is to address this limitation by evaluating the broadcast strategy of Australia's two largest professional sporting organisations, the methodology of which is now discussed. 


\section{Sport Broadcasting and the Case Study Context}

The implementation of effective broadcast strategy has been particularly credited with the success and growth of the AFL over the past three decades (Stewart, Nicholson \& Dickson (2005). Stewart and Dickson (2007) also draw a direct connection between the AFL's broadcast strategy and the league's successful national expansion during this period. In contrast, the inability to successful expand nationally over the past 20 years has been a constant criticism of the NRL (Rowe, 2010). East (2012) describes the AFL's broadcast strategy as mixed position, utilising both FTA and subscription television to maximise both revenue and national reach (a strategy which has similarly been adopted by the NRL). This strategy has been necessitated by Australia's regulatory environment (Fujak, 2012). A comparative evaluation of global sport regulation by Smith, Evens, and Iosifidis (2015) indicated that Australia can be categorised as among the most regulated sports broadcasting markets, owing to its 'first choice' approach towards FTA broadcasters as well as an exclusivity list surpassing 1,800 sporting events annually as compared to 100 events in many European countries.

A key influence on broadcast strategy within Australia is the structure of the sports marketplace. Notably, the AFL and NRL are characterised by collective broadcasting agreements and shared broadcast revenue (Stewart et al., 2005). As observed by Turner (2012) there is a consensus among these stakeholders that centralised management is the best structure to manage broadcast rights and set strategy, despite conflicts between balancing broadcaster, league and club needs. Such conflicts were identified by Jakee, Kenneally and Mitchell (2010), who determined there were asymmetries in the distribution of favourable playing slots among AFL clubs (in favour of 'high profile' teams) which was likely to cause significant intra-club financial variance. This financial inequity manifested both directly through gate receipts and indirectly through sponsorship attractiveness via television 
exposure (Jakee et al., 2010). Despite such challenges, clubs forgo significant autonomy to maximise their own exposure and instead allow league management to set strategy and act as their agent (Stewart \& Dickson, 2007). Therefore, for the purposes of this study, the dimensions of broadcast strategy to be evaluated are guided by the objectives set by the AFL and NRL. Specifically, the effectiveness of broadcast strategy is measured against the established strategic goals outlined in each league's strategic plans. A synopsis of these strategic plans is provided below.

NRL. The NRL implemented a five-year strategic plan covering the period 2005 to 2009 , within which time the negotiation of the terms for the 2007 to 2012 broadcast rights were finalised (National Rugby League, 2005). The strategic plan had five central priority areas with 53 interconnected objectives. The priority areas included elite development programs, quality competition, profiling the game, strong community involvement and financial strength. In relation to broadcast strategy the listed objectives below were the most relevant.

Objective 1: Ensure as many people as possible are exposed to media coverage of Rugby League

Objective 2: Foster interest in important Rugby League regions by ensuring direct exposure to the game in those locations

Objective 3: Provide compelling value to our partners to ensure their continued investment in the game.

AFL. The AFL produced a ten year strategic direction in 2005 which encompassed five pillars: financial viability, competition and the game, increased participation, community and customer relations and a collaborative industry (Australian Football League, 2006). 
Among the 15 clearly defined objectives the following were the most relevant to broadcast strategy:

Objective 1: Continue building a strong financial base for the competition while maximising economic benefits for all stakeholders.

Objective 2: Stronger AFL competition presence in New South Wales and Queensland

Objective 3: Strengthen connection to the community.

\section{Methodology}

\section{Study Background}

The research adopted a case study methodology. This approach was selected with due consideration to the research questions and the context within which the data was placed. Yin (2013) provides three criteria by which to determine the appropriateness of case study research, surrounding the form of the research questions posed, the degree of behavioural control within the research and the contemporariness of the event in question. While this study involves numeric quantification, often considered the domain of survey and archival analysis methods, here it is performed for the purposes to explore 'how' and 'why' research questions, which is well suited to case study research. In respect to behavioural control and contemporary events, the dataset is composed of secondary data of organisational information that pertains to an on-going contemporary phenomenon, which once again is consistent with contexts that engender themselves to case study research. 
The decision to simultaneously examine the AFL and NRL centred on both methodological and pragmatic advantages. Woodside (2010) notes that 'deep understanding of the actors, interactions, sentiments, and behaviours occurring for a specific process through time should be seen as the principal objective by the case study researcher' (p.6). Therefore, given that these two codes represent the largest actors to undertake the activity of interest, the analysis of both leagues allows for a deeper understanding via identification of the commonalities and distinctions between both entities (Bryman, 2008). From a practical perspective, these two football codes represent the dominant media share of the Australian football industry, being the only football codes televised on FTA on a weekly basis during the timeframe under examination. Second, the broadcast strategies of each organisation are potentially influenced by similar environmental contexts. Therefore the study of one football code without consideration of its central competitor would have been an incomplete study. In order to provide further context, a brief organisational overview of both the AFL and NRL is outlined below.

The AFL is the governing organisation for the sport known as Australian Rules football, which developed during the 1840's predominantly in the southern Australian state called Victoria (Cashman, 2010). Having historically been played in the southern and western states of Australia, the sport has expanded into the northern states with a now national 18 team competition. The AFL is regarded as the most successful elite sport competition in Australia. This success has been based upon significant governance reform starting in the 1980s when the AFL moved from a delegate system to an independent commission in 1985 (Fujak \& Frawley, 2013). The AFL has leveraged this governance reform through the establishment of a strategic vision to aggressively grow the game across the nation (Stewart, Nicholson \& Dickson, 2005). Not only does the AFL generate the largest broadcast revenue in Australian sport it also has the largest sponsorship portfolio of any of the football codes 
played in the nation (Stewart, 2007). The AFL employs more than 400 full-time staff making it the biggest single sport employer in the country and in 2013 earned revenue of A\$446 million (Australian Football League, 2014).

The NRL is the governing body for the sport of rugby league in Australia. The sport was established in Australia in 1907 following its creation in England as a breakaway from rugby union in 1895 (Cashman, 2010). The sport has been mainly played in the north-eastern Australian states of New South Wales and Queensland. The elite competition has experienced periods of expansion and contraction but remains largely embedded within north-eastern Australia (Fujak \& Frawley, 2013). Today the competition consists of 16 teams from NSW, Queensland, Canberra, Victoria and New Zealand. In 2012, the sport went through a major governance transformation with the establishment of an independent commission to oversee management of the game (Fujak \& Frawley, 2014). Prior to this governance restructure the NRL was $50 \%$ owned by News Corporation. This was the result of a peace treaty in 1998 between the company and Rugby League's governing body at the time, the Australian Rugby League, which resulted in the reunification of the sport after a season of rival competitions (Cashman, 2010). It is noteworthy that News Corporation today is the owner of pay-TV provided Fox Sports.

The tracking period of 2007 to 2011 was chosen due to factors both methodological and practical. This timeframe represented the entirety of the AFL's most recently completed commercial broadcast agreement, while the NRL's broadcast contract commenced in 2007 but ended in 2012, a year later in comparison to the AFL's (Fujak, 2012). Prior to the 2007 season, the broadcast environment for both the AFL and NRL was drastically different, impairing cross-code comparison and longitudinal analysis. Season 2007 saw the expansion of the NRL competition from 15 to 16 teams. This resulted in not only an additional game per round, but also a significant change in scheduling, resulting in a different distribution of bye 
game allocations and also a change in the standard weekly timeslots in which fixtures were contested (Fujak, 2012). Season 2007 also saw a dramatic change in AFL scheduling, with a move from incumbent rights holder Channel Nine to a joint broadcaster arrangement with Channel Seven and Channel Ten, which had the result of a greater distribution of coverage on FTA television (Fujak \& Frawley, 2013, 2014).

\section{Data Background}

The study utilised data collected by television ratings research organisations, OzTAM and Regional TAM. These two firms are the sole providers of television rating information in the Australian marketplace. Each lays claim to being the central medium by which television media is bought and sold (Fujak, 2012). The ratings collection process adopted by both research organisations endeavours to achieve timely, valid and representative data through a seven stage process: defining the panel, recruiting panel homes, installing the measurement technology, retrieving the data, data management, data integration, and data release (OzTam, 2010). Combined, OzTAM and Regional TAM utilise a sample size of over 5,000 households and 14,000 individuals within ten regions across Australia. This represents a superior per-capita sample size in comparison to other markets such as the UK, Italy, Indonesia, and Greece (Fujak, 2012).

When joined together, the ten measured markets of OzTAM and Regional TAM represent the national viewing audience in Australia. However, both organisations warn against amalgamating their datasets due to some minor overlap in panel regions (Fujak \& Frawley, 2013). It is important to observe that the Australian FTA broadcast market is concentrated between three commercial networks that broadcast within all local markets. Therefore, while decisions about content and coverage are made at a regional level, the content is owned and broadcast by national providers (or their alliance partner). A 
comparison of OzTAM and Regional TAM national population estimates and the Australian Bureau of Statistics (ABS) estimates is provided in Table 1.

\section{[Insert Table 1 about here]}

The dataset is a collection of 'average' audiences for each broadcast in each market in which the fixture was telecast. The average audience is defined as the "average number of people in a target market who were watching a specific event or time band each minute, expressed in absolute figures for that demographic" (OzTAM, 2010, p.1). For the purposes of the dataset, the 'specific event' is the match itself ignoring any pre-match or post-match programmes. While the dataset excludes replays, matches shown on delay on FTA television which were the first airing of the match were included (OzTAM, 2010). This was largely due to the regularity in which NRL matches were aired on a considerable delay in non-heartland markets, a notable point of difference between the two leagues.

\section{Findings and Discussion}

\section{Broadcast Slots and Geographic Reach}

The results revealed that the leagues' broadcast structures differ in broadcast slots, geographical reach, and broadcast days. Thus, the analysis of AFL and NRL broadcast ratings illuminate several key distinctions between the codes in terms of the application of potential broadcast and scheduling strategy. Notably, the codes held distinctly different broadcast slot dispersions in several respects. The AFL recorded a higher FTA broadcast rate, equating to a $57 \%$ coverage compared to the NRL's rate of $39 \%$, ensuring that significantly more AFL content was available free to the general population. More critically in evaluating broadcast strategy, the codes maintained distinctly different practices when dispersing their broadcasts on FTA television. The NRL, for instance, took a broad-brush national approach to FTA 
broadcasting, with matches in most cases selected for national FTA broadcast. In contrast, the AFL took what can be termed a regionally targeted approach to broadcasting in which they aired fewer national telecasts and instead targeted particular markets with coverage of specific teams. From 1,005 NRL premiership fixtures played during the period 2007 to 2011 , only $40 \%$ of matches were telecast on FTA television. Yet among these $40 \%$ of matches, $92 \%$ of these were telecast nationally across all ten broadcast markets. In contrast, $92 \%$ of AFL matches were shown into at least one FTA broadcast markets during the same period, but only $33 \%$ of these matches were broadcast nationally. Figure 1 illustrates the differing broadcast coverage distribution of the AFL and NRL.

[Insert Figure 1 about here]

Another key difference between the two codes' broadcast strategy was the distribution of FTA broadcasting of individual clubs in their local markets. As illustrated in Table 2, every non-Victorian AFL club had nearly all their regular season matches broadcast into their local market during the research period. Focusing specifically on the scheduling of clubs located within the expansion markets of both leagues, further distinctions in broadcast structures are apparent. In the case of AFL, not only were expansion market teams Brisbane Lions and Sydney Swans broadcast on FTA television on nearly all occasions, but they were all done so live in 2010 and 2011. In contrast, NRL expansion market club Melbourne Storm were only telecast on FTA television on $21 \%$ of occasions during this time period, of which only $40 \%$ was live. Among the $60 \%$ of occasions in which the Melbourne Storm received delayed FTA coverage in their local market, the average length of delay from kick off to telecast was six hours and five minutes. Despite the AFL telecasting local teams extensively into local markets, this came at a trade-off for national exposure, with six of seven nonVictorian teams featuring in the bottom eight in terms of overall FTA exposure. Collectively, non-Victorian teams held an average national FTA broadcast rate of $44.25 \%, 28 \%$ less than 
the national FTA rate of Victorian AFL teams, which stood at $61.05 \%$. The AFL strategy of broadcasting local teams into local markets was distinct from the NRL who, as previously outlined, transmitted a national broadcast that was nearly always shown across all 10 national broadcast markets.

[Insert Table 2 about here]

Although it is evident that significant demand exists for AFL and NRL broadcast content, analysis of broadcast delays suggests that such demand is geographically asymmetrical. Comparison of the average broadcast start times across the five metropolitan capital cities seems to suggest that broadcasters are sceptical in attempting to appeal to the non-traditional markets. Table 3 provides a reconciliation of the average telecast start time for matches played on Friday night with a scheduled start time of 7:30pm (for the Australian Eastern seaboard). What is clear is that both leagues are yet to attain mainstream appeal in non-heartland markets, evidenced by the broadcasters electing to telecast matches on delays of up to four hours in each league.

[Insert Table 3 about here]

\section{Broadcast Days}

The second element of exclusivity that offered a stark contrast between the AFL and the NRL broadcast agreements concerned scheduling. As observed by Noll (2007), an "increase in games scheduled at or near the same time tends to reduce the average audience because some viewers will be more selective in the matches that they watch as the number of matches per day or week grows" (p. 407). In the NRL, 74\% of matches (excluding those held on public holidays) broadcast on Foxtel were done so on days where there was no alternate FTA televised match. A key driver for this was the re-introduction of Monday Night Football 
(MNF) in 2007, which along with "Super Saturday" resulted in the NRL providing Foxtel two days per round in which it held exclusive transmission of NRL match content (Figure 2). In contrast, the AFL provided little such exclusivity to Foxtel, as there was no day of week on which AFL supporters would require a Foxtel subscription to be able to view an AFL match in most markets.

[Insert Figure 2 about here]

\section{Subscription Broadcasters}

The findings of this study also revealed answers regarding the implications of broadcast structures on league stakeholders. While subscriber television services generate income from advertising, the profitability of which is linked to audience size and demography, the dominant income stream of such operators is subscriber revenue (Noll, 2007). This is reflected in Consolidated Media's 2011 Annual Report, in which Foxtel subscriber revenue accounted for $\mathrm{A} \$ 1.81$ billion in comparison to advertisings share of A \$0.33 billion of total revenue earned for the 2011 financial year (Consolidated Media Holdings, 2011). As discussed earlier, the impact of sport in driving subscriber media platforms has been well made (Gratton \& Solberg, 2007). This is further illustrated by Foxtel's annual reports in which sport accounted for 98 of the top 100 subscription television programs during the 2011 financial year (Consolidated Media Holdings, 2011).

Despite the well-known financial significance of subscription rates to overall revenue, the AFL and NRL provided directly contrasting broadcasting conditions within which Foxtel operated. The AFL's regional targeting strategy of providing local FTA coverage to local teams outside of Victoria ultimately resulted in the dilution of exclusivity towards both their FTA (Channel Seven and Chanel Ten) as well as their subscription provider (Fox Sports), particularly as compared to the NRL's agreements with its respective partners (Channel Nine 
and Fox Sports). In the case of AFL, each match shown live on Foxtel $(n=443)$ was simulcast into on average 2 FTA broadcast markets, with only $17 \%$ of live Foxtel matches being exclusive to Foxtel nationally. The presence of simulcasts arose from the qualitative element of the agreement identified by Stewart and Dickson (2007) which ensured all matches involving clubs from outside of Victoria were broadcast into the respective team's home broadcast markets during the period (Table 2). In contrast, no NRL matches were simulcast between Network Nine and Foxtel, ensuring a high level of exclusivity for each partner. Furthermore, the NRL also proved to be more accommodating to their broadcasters in terms of the distribution of broadcasts across the weekly schedule. As previously mentioned, the reintroduction of MNF in 2007, contributed to ensuring that $74 \%$ of matches broadcast live on Fox Sports occurred on days where there was no FTA alternative telecast to look forward to.

From Foxtel's perspective of attempting to leverage AFL broadcast rights to drive subscriber growth, the presence of guaranteed local team FTA transmission outside of Victoria resulted in approximately $72 \%$ of the viewing population (based on 2010 and 2011 populations) having access to watch their local team play on FTA television every week. Such a scenario is in direct conflict with the findings of Johnsen and Solvoll (2007), who observed that private/subscriber channels are particularly dependent on showing popular football clubs to attract viewers. Furthermore, as noted by Noll, "because every team is likely to be more popular at home than in other areas, local rights can capture most - perhaps nearly all - of the value of the national rights for many teams' (2007, p. 413).

A further impact on subscription demand was the overall level of FTA coverage in the respective heartland markets of Sydney (NRL) and Melbourne (AFL). During the period, the 10 New South Wales-based NRL clubs held an average FTA broadcast rate of $41 \%$ in Sydney, two-thirds the rate of Victorian AFL clubs which averaged a $63 \%$ broadcast rate in 
Melbourne. The outcome of these differing broadcast rates was that only one AFL club, the North Melbourne Kangaroos, averaged a higher number of Foxtel exclusive matches per season than any NSW-based NRL club. Returning to Johnsen and Solvoll's (2007) observation that the selection of popular clubs on private/subscription channels is a key driver of demand, Collingwood Magpies' supporters were provided with little motivation to acquire a subscription, with only 3.6 matches per season shown exclusively on Foxtel at a pro-rata subscription cost of A $\$ 323.33$ per game. In contrast, a Foxtel subscription would offer Cronulla Sharks' fans a significantly stronger value proposition, given their average of twenty games per season telecast on Foxtel at a pro-rata cost of A $\$ 58.20$ per game (Table 4).

\section{[Insert Table 4 about here]}

Comparison of subscriber levels across Australia's metropolitan capital cities during the period lends support to the notion that the NRL's more exclusive broadcast structure resulted in increased subscriber rates within their local markets. Sydney, a heartland NRL market, held the greatest subscription television penetration rate of all Australian metropolitan cities in both percentage terms $(37.5 \%)$ and in terms of aggregate households (622,900 homes). The combined average household subscriber rate in the NRL heartland markets of Sydney and Brisbane was $28 \%$ greater than that of the AFL markets of Melbourne, Adelaide and Perth (35\% versus 27\%), equating to an additional 182,000 subscribing households within NRL heartland markets. Therefore, it would appear that the provisions within NRL broadcast agreement were successful in aiding Foxtel to increase subscriber rates in heartland markets. Although beyond the scope of this paper, given News Corporation's joint ownership of both the NRL and Foxtel/Fox Sports, it is distinctly possible that this interrelationship assisted the organisation to leverage a favourable broadcasting outcome. 


\section{FTA Broadcasters}

Evaluating the performance of FTA broadcasters and their selection of sport programming can be a difficult process as ratings, whilst very important, are not the only factor that needs to be evaluated (Fujak, 2012). Factors such as 'spill over' into other content as well as contribution to the network 'brand' have been shown to be important considerations in bidding for sports content (Solberg \& Gratton, 2008). The FTA performance of the AFL and NRL within this discussion however is centred on the quantitative evaluation of their ratings during the aforementioned period. Because AFL and NRL matches hold different broadcast durations (three and two hours respectively), there is a need to standardise each code's ratings into a common unit to allow for fair comparison. This is achieved through analysis of not only ratings but also duration. This was the method adopted by the International Olympic Committee in their calculations for their global audience reports to account for events of differing duration prior to shifting to an 'average minute rating' method in 2014 (IOC, 2014).

Due to the significantly longer average duration of AFL matches compared to the NRL and a greater overall FTA coverage rate, the AFL generated $67 \%$ more FTA viewing hours than the NRL (see Table 5). However, due to the considerably larger size of their rights fee (146\% more than NRL), the AFL was the significantly more expensive sport product. Based on each code's respective rights fee and viewer minutes, each dollar spent on broadcast rights by joint FTA partners, Channel Seven and Channel Ten, bought nearly 202 minutes of AFL viewership. In contrast, each dollar invested bought Channel Nine 297 minutes of NRL viewership, equating to a $47 \%$ better value proposition for the network.

[Insert Table 5 about here] 


\section{Supporters}

The impact of broadcast strategy on fans during the period was largely contingent on the club in question. Fans of AFL clubs generally received greater opportunity to watch their team without a supplementary pay television subscription. Despite a shorter season, the AFL telecasts an average of 106 matches annually into each market compared to the NRL's 79. The greatest beneficiaries of the AFL broadcast strategy were fans located outside of Victoria, who received close to $100 \%$ FTA coverage of their local team during the examined period. This supports the work of Stewart and Dickson (2007) who note that the AFL has historically used broadcasting as a strategic tool in attracting new fans, many of whom live outside of Victoria. Instead of just maximising the financial return from rights fees the AFL established a qualitative dimension within its television contracts. This dimension particularly aimed to guarantee the level of coverage in non-traditional markets such as the northern states of Australia. "In effect the AFL was telling its broadcast partners that it was prepared to forsake additional revenue in exchange for greater exposure in these markets" (p. 93).

However, even within the Victorian market, fans were not 'starved' of content, with nine of ten Victorian AFL teams having at least half their games telecast on FTA television. In contrast, no New South Wales based NRL team recorded a FTA broadcast rate above 50\% during the examined period. Brisbane Broncos supporters were likely to be the only NRL fab group satisfied by the amount of coverage for their club, having access to $74 \%$ of matches through FTA television. In contrast, Canberra Raiders (10\%) and the Cronulla Sharks (16\%) fans are likely to feel the most aggrieved by limited FTA coverage.

The varying degree in which fans were the beneficiaries of coverage is perhaps best reflected in Table 4. During the period, Victorian fans of the Collingwood Magpies on average were able to view 18 of 22 potential matches on FTA television. In contrast, many 
fans of most New South Wales clubs would have considered a subscription package a necessity if they desired to watch their team on television, with the ten clubs holding a collective average of 14 games covered exclusively by Fox Sports at a cost of A $\$ 85.34$ per game. Therefore, on the basis of access to match content, AFL fans were distinct winners and thus the NRL fans the distinct loser from the broadcast structures their respective leagues implemented.

\section{Leagues and Clubs}

The AFL was able to secure a significantly superior financial return on their broadcast agreement compared to the NRL. More significantly, the AFL was able to achieve this despite providing less favourable terms to its broadcasters. The NRL entered into a longer deal and provided superior broadcasting conditions to both its FTA and subscription broadcaster yet received a smaller rights fee. After factoring for the contribution to value generated by secondary competitions, the AFL received A $\$ 661,735$ per premiership game screened live (but exclusively on just $17 \%$ of occasions) to Foxtel while the NRL sold live and fully exclusive fixtures at the price of $\mathrm{A} \$ 350,893$ per game. On FTA television, the AFL received approximately 49.5 cents for every 100 minutes of content watched per viewer while the NRL received 33.7 cents for every 100 minutes of content watched per viewer. Although outside the scope of this research, given the gulf in rights valuation between the codes was not supported quantitatively, it is evident that further research is warranted to understand other factors at play in determining broadcast right valuations.

While the NRL broadcast agreement appeared to have negative game development trade-offs, the AFL's insistence on a qualitative dimension to its broadcast coverage ensured positive game development outcomes (Stewart \& Dickson, 2007). Fan development models have held a general consensus that television and media coverage are particularly important 
engagement tools, particularly among less engaged fans. Notably, television viewership has been shown to be a key pillar in fan development at this phase for both children and adults. In respect to children, Kolbe and James (2000) observe that fathers are the key socialising agents, either by talking about or watching specific sports and teams on television while Funk and James (2001) observe that media content is important for adolescent and adult awareness due to increased access. In this context therefore, it is apparent that initiatives to improve the quality and reach of coverage for AFL expansion teams such as the Sydney Swans and Brisbane Lions are embedded within a targeted game development strategy.

\section{Alignment of Broadcast Structures and League Objectives}

Three central strategic objectives were identified in the NRL strategic plan that concerned the implementation of broadcast strategy for the period 2007 to 2011. In relation to Objective 1, 'ensuring as many people as possible are exposed to media coverage of Rugby League', it would appear that the league was largely unsuccessful in fulfilling this objective through television media. Given that nearly $60 \%$ of matches were telecast exclusively on the pay-TV platform, which held a $35 \%$ penetration rate in heartland markets, it is apparent that maximum media exposure was not achieved. In relation to Objective 2, 'Foster interest in important Rugby League regions by ensuring direct exposure to the game in those locations', one of two conclusions can be made. Firstly, for the league to have fulfilled this objective, then one can only conclude that New South Wales and Queensland are the only important Rugby League regions in Australia. This was evident by the distinctions in coverage quality between these two states and the remaining states, whereby coverage was on average delayed by four hours. Alternatively, if the league considers any of their non-traditional markets as 'important Rugby League regions', then the organisation has failed in their objective to foster interest in these areas via broadcast media. The NRL would seem to have been more successful in fulfilling Objective 3 in relation to its media partners: 'Provide compelling 
value to our partners to ensure their continued investment in the game'. Here, the analysis has identified that through the delivery of exclusivity practices, the league was able to deliver value to its broadcast partners, particularly when compared to the AFL.

The AFL appeared to achieve considerably stronger alignment between their strategic objectives and broadcasting outcomes. In relation to Objective 4, 'Continue building a strong financial base for the competition while maximising economic benefits for all stakeholders', the league was able to negotiate a significantly higher financial return despite offering fewer concessions to broadcasters. After the first year of the new broadcast agreement, the league's annual operating surplus increased 45\% in 2007 to A $\$ 202$ million and by 2011 it reached A\$234 million (Australian Football League, 2008, 2012). The league also had success with Objective 5, 'Stronger AFL competition presence in NSW and Queensland'. The league successfully ensured live coverage of Sydney Swans and Brisbane Lions matches on the FTA platform in their respective states (New South Wales and Queensland), effectively ensuring the potential audience reach was maximised. Mitigating this success however, AFL telecasts not featuring the above mentioned home teams continued to be telecast on considerable delay in New South Wales and Queensland, to a similar degree to the NRL. With references to the AFL's Objective 6, 'Strengthen connection to the community' the league ensured that fans in every market received access to desirable content. In the case of heartland markets, the league ensured that fans were exposed to significantly high levels of FTA content while in nonheartland markets, the league ensured that local teams received maximum available exposure.

\section{Conclusion}

With the recently signed AFL and NRL broadcast deals worth in excess of one billion Australian dollars each (over five years), it is evident that well defined broadcasting strategies must increasingly be a focal point for competing national sport leagues. This study attempted 
to quantify broadcast strategy within the Australian sporting marketplace, identifying distinctions between leagues in terms of coverage exclusivity and geographic reach and discussing the corresponding implications for league stakeholders.

The study finds that the AFL has been the more successful league in operationalising their broadcast strategy to meet the stated league objectives. The AFL's success derived from enacting specific qualitative features while still recording a considerable financial return. The AFL ensured that the fans of the game in key markets had access to desirable telecast coverage and they increased coverage from previous broadcast agreements. These qualitative features in fact contradict the established broadcast revenue maximisation principles established by Noll (2007). Specifically, the AFL enacted two specific revenue reducing broadcast strategies: scheduling of matches near the same time and across broadcaster platforms as well as telecast home teams into home markets on FTA television. Therefore, it can be questioned to what degree the league could have in fact further increased their broadcast rights had they chosen to disregard qualitative league objectives similar in manner to the NRL.

Despite the underlying ratings metrics suggesting the AFL and NRL to be similarly attractive broadcast products, the NRL achieved a significantly smaller financial return from its broadcasters, the reasons for which may prove worthy of future investigation. This lesser return was despite the NRL enacting broadcast strategies in accordance with the revenue maximising principles proposed by Noll (2007). These strategies, which ensured each host broadcaster held considerable exclusivity around game scheduling and local rights, appeared to be misaligned to the league's game development objectives.

This study finds that the AFL has been the more successful Australian sporting league in leveraging its broadcasters to achieve both financial and strategic outcomes. However, 
while this paper utilised broadcast ratings to measure the value created for broadcasters, television ratings alone do not provide the complete picture of how total broadcaster value is created or how rights fees are negotiated between leagues and broadcasters. Further research therefore is required to understand more fully how broadcast negotiations take place in practice. 


\section{References}

Andreff, W., \& Staudohar, P. (2000). The evolving European model of professional sports finance. Journal of Sports Economics, 1(3), 257-276.

Australian Bureau of Statistics. (2012). Australian demographic statistics. Dec 2011. (cat no. 3101.0). Canberra, Australia: ABS.

Australian Football League. (2006). 2005 annual report. Melbourne, Victoria: Australian Football League,

Australian Football League. (2008). 2007 AFL annual report. Melbourne, Victoria: Author. Australian Football League. (2012). Annual report 2011. Melbourne, Victoria: Author. Australian Football League. (2014). Annual report 2013. Melbourne, Victoria: Author.

BBC. (2015). Premier League TV rights: Sky and BT pay $£ 5.1$ bn for live games Retrieved from http://www.bbc.com/sport/0/football/31357409

Borland, J., \& Macdonald, R. (2003). Demand for sport. Oxford Review of Economic Policy, 19(4), 478-502.

Bryman, A. (2008). Social research methods. Oxford, UK: Oxford University Press.

Cashman, R. (2010). Paradise of sport ( $2^{\text {nd }}$ ed.). Petersham, NSW: Walla Walla Press.

Consolidated Media Holdings. (2011). 2011 annual report. Sydney: Author.

East, B. (2012). Australian Rules Football in a commerical era: catering for theatregoers and tribals. Petersham: Walla Walla Press.

Feddersen, A., \& Rott, A. (2011). Determinants of demand for televised live football: Features of the German National Football Team. Journal of Sports Economics, 12(3), $352-369$.

Forrest, D., Simmons, R., \& Buraimo, B. (2005). Outcome uncertainty and the couch potato audience. Scottish Journal of Political Economy, 52(4), 641-661. 
Forrest, D., Simmons, R., \& Szymanski, S. (2004). Broadcasting, attendance and the inefficiency of cartels. Review of Industrial Organization, 24(3), 243-265.

Frawley, S., \& Adair, D. (2013). Managing the Olympics. London: Palgrave Macmillan.

Fujak, H. (2012). An analysis of broadcasting and attendance in the Australian Football Industry (Unpublished master's thesis). University of Technology, Sydney.

Fujak, H., \& Frawley, S. (2013). The Barassi Line: Quantifying Australia's great sporting divide. Sporting Traditions, 30(2), 93-109.

Fujak, H., \& Frawley, S. (2014). The relationship between television viewership and advertising content in Australian Football broadcasts. Communication and Sport. doi: $10.1177 / 2167479514522792$

Funk, D., \& James, J. (2001). The Psychological Continuum Model: A conceptual framework for understanding an individual's psychological connection to sport. Sport Management Review, 4(2), 119-150.

Gratton, C., \& Solberg, H. A. (2007). The economics of sports broadcasting. London: Routledge.

Hammervold, R., \& Solberg, H. (2006). TV sports programs- Who is willing to pay to watch? Journal of Media Economics, 19(3), 147-162.

Hoehn, T., \& Lancefield, D. (2003). Broadcasting and sport. Oxford Review of Economic Policy, 19(4), 552-568.

IOC. (2014). Olympic marketing fact file. Zurich: Author.

Jakee, K., Kenneally, M., \& Mitchell, H. (2010). Asymmetries in scheduling slots and gameday revenues: An example from the Australian Football League. Sports Management Review, 13(1), 50-64.

Johnsen, H., \& Solvoll, M. (2007). The demand for televised football. European Sport Management Quarterly, 7(4), 311-335. 
Kolbe, R. H., \& James, J. D. (2000). An identification and examination of influences that shape the creation of a professional team fan. International Journal of Sports Marketing \& Sponsorship, 2(1), 23-27.

Macdonald, R., \& Booth, R. (2007). Around the grounds: A comaprative analysis of football in Australia. In B. Stewart (Ed.), The games are not the same: The political economy of football in Australia (pp. 236-331). Melbourne: Melbourne University Press.

Masters, R. (2015). Why the NRL and AFL are looking at \$2 billion deals in next TV negotiations Retrieved from http://www.smh.com.au/rugby-league/league-news/whythe-nrl-and-afl-are-looking-at-2-billion-deals-in-next-tv-negotiations-20150306$\underline{13 \mathrm{x} 0 \mathrm{kx} \cdot \mathrm{html}}$

National Rugby League. (2005). That's my game: Rugby League's five year strategic plan 2005-2009. Sydney, Australia: Author.

Neale, W. C. (1964). The peculiar economics of professional sports. Quarterly Journal of Economics, 78(1), 1-14.

Nicholson, M. (2007). Sport and the media: managing the nexus. Oxford, Burlington, MA: Elsevier.

Noll, R. (2007). Broadcasting and team sports. Scottish Journal of Political Economy, 54(3), 400-421.

OzTAM. (2010). OzTam ratings brochure. Sydney: Author.

OzTAM. (2013). Universal estimates year 2013. Sydney: Author.

Rowe, D. (1996). The global love-match: Sport and television. Media, Culture \& Society, $18(4), 565-582$.

Rowe, D. (2010). The stuff of dreams, or the dream stuffed? Rugby League, media empires, sex scandals, and global plays. In R. Cashman (Ed.), Tails from Coathanger City: Ten 
years of Tom Brock Lectures (pp. 177-200). Sydney: Australian Society for Sports History.

Rowe, D., \& Gilmour, C. (2009). Getting a ticket to the world party: Televising soccer in Australia. Soccer \& Society, 10(1), 9-26.

Smith, P., Evens, T., \& Iosifidis, P. (2015). The regulation of television sports broadcasting: a comparitive analysis. Media, Culture \& Society. doi: 0163443715577244

Solberg, H., \& Hammervold, R. (2008). TV sports viewers- Who are they? Nordicom Review, 29(1), 95-110.

Stewart, B., \& Dickson, G. (2007). Crossing the Barassi Line: The rise and rise of Australian Football. In B. Stewart (Ed.), The Games are not the same: The political economy of football in Australia (pp. 71-113). Melbourne: Melbourne University Press.

Stewart, B., Nicholson, M., \& Dickson, G. (2005). The Australian Football League's recent progress: A study in cartel conduct and monopoly power. Sport Management Review, $8,95-117$.

Stewart, B., \& Smith, A. (2000). Australian sport in a postmodern age. International Journal of the History of Sport, 17(2), 278-304.

Szymanski, S. (2006). The economic evolution of sport and broadcasting. The Australian Economic Review, 39(4), 428-434.

Tainsky, S. (2010). Television broadcast demand for National Football League contests. Journal of Sports Economics, 11(66), 629-640.

Turner, P. (2012). Regulation of professional sport in a changing broadcasting environment: Australian club and sport broadcaster perspectives. Sport Management Review, 15(1), 43-59.

Turner, P., \& Shilbury, D. (1997). Sport on television: A study of the Australian Football League television rights. Sport Marketing Quarterly, 6(3), 55-62. 
Turner, P., \& Shilbury, D. (2005). Determining the professional sport broadcasting landscape: An Australian Football club perspective. Sport Management Review, 8(2), 167-193.

Woodside, A. G. (2010). Case study research: Theory, methods and practice. Bingley: Emerald.

Yin, R. (2013). Case study research: Design and methods (5 $5^{\text {th }}$ ed.). Los Angeles: Sage. 
Table 1

Television Ratings versus Australian Bureau of Statistics Population Estimates

\begin{tabular}{llccc}
\hline \multicolumn{1}{c}{ Region } & \multicolumn{1}{c}{ Sub-Region } & TAM & ABS & Variance \\
\hline NSW+ ACT & $\begin{array}{l}\text { Sydney } \\
\text { Northern NSW } \\
\text { Southern NSW }\end{array}$ & $8,124,000$ & $7,618,400$ & $6.6 \%$ \\
\hline Victoria & $\begin{array}{l}\text { Melbourne } \\
\text { Regional }\end{array}$ & $5,699,000$ & $5,574,500$ & $2.2 \%$ \\
\hline Queensland & $\begin{array}{l}\text { Brisbane } \\
\text { Regional }\end{array}$ & $4,746,000$ & $4,513,000$ & $5.2 \%$ \\
\hline South Australia & $\begin{array}{l}\text { Adelaide } \\
\text { Regional }\end{array}$ & $1,408,000$ & $1,654,000$ & $(14.9 \%)$ \\
\hline Western Australia & $\begin{array}{l}\text { Perth } \\
\text { Regional }\end{array}$ & $2,354,000$ & $2,387,200$ & $(1.4 \%)$ \\
\hline Tasmania & Tasmania $^{\mathrm{b}}$ & 510,000 & 511,700 & $(0.3 \%)$ \\
\hline Northern Territory & & - & 232,400 & - \\
\hline Total & & $22,841,000$ & $20,837,200$ & $9.6 \%$ \\
\hline
\end{tabular}

${ }^{a}$ Regional TAM does not measure audiences in Northern Territory or Regional SA. ${ }^{b}$ Regional TAM introduced Regional WA in 2011. Regional WA data was not available. 
Table 2

FTA Broadcast Rate by Team in their Home Market and Nationally

\begin{tabular}{|c|c|c|c|}
\hline Teams & Market & Home $\%$ & National \% \\
\hline \multicolumn{4}{|l|}{$\overline{\mathrm{AFL}}$} \\
\hline \multicolumn{4}{|l|}{ Non-Victorian Teams } \\
\hline Sydney Swans & Sydney & $100 \%$ & $61 \%$ \\
\hline Gold Coast Suns & Brisbane & $100 \%$ & $49 \%$ \\
\hline Brisbane Lions & Brisbane & $99 \%$ & $46 \%$ \\
\hline Adelaide Crows & Adelaide & $99 \%$ & $41 \%$ \\
\hline Port Adelaide Power & Adelaide & $99 \%$ & $40 \%$ \\
\hline West Coast Eagles & Perth & $98 \%$ & $39 \%$ \\
\hline Fremantle Dockers & Perth & $99 \%$ & $34 \%$ \\
\hline \multicolumn{4}{|l|}{ Victorian Teams } \\
\hline Collingwood Magpies & Melbourne & $84 \%$ & $78 \%$ \\
\hline Carlton Blues & Melbourne & $70 \%$ & $68 \%$ \\
\hline Geelong Cats $^{\mathrm{a}}$ & Melbourne & $69 \%$ & $66 \%$ \\
\hline Essendon Bombers & Melbourne & $67 \%$ & $63 \%$ \\
\hline St Kilda Saints & Melbourne & $65 \%$ & $63 \%$ \\
\hline Hawthorn Hawks & Melbourne & $65 \%$ & $59 \%$ \\
\hline Melbourne Demons & Melbourne & $56 \%$ & $58 \%$ \\
\hline Western Bulldogs & Melbourne & $57 \%$ & $57 \%$ \\
\hline Richmond Tigers & Melbourne & $54 \%$ & $54 \%$ \\
\hline North Melbourne & Melbourne & $45 \%$ & $45 \%$ \\
\hline \multicolumn{4}{|l|}{ NRL } \\
\hline \multicolumn{4}{|l|}{ Non-New South Wales } \\
\hline Brisbane Broncos & Brisbane & $74 \%$ & $72 \%$ \\
\hline Gold Coast Titans & Brisbane & $40 \%$ & $38 \%$ \\
\hline Melbourne Storm & Melbourne & $26 \%$ & $26 \%$ \\
\hline North Queensland & Brisbane & $26 \%$ & $25 \%$ \\
\hline New Zealand Warriors & - & - & $12 \%$ \\
\hline \multicolumn{4}{|l|}{ New South Wales } \\
\hline Wests Tigers & Sydney & $54 \%$ & $53 \%$ \\
\hline St. George Illawarra & Sydney & $53 \%$ & $52 \%$ \\
\hline Parramatta Eels & Sydney & $52 \%$ & $50 \%$ \\
\hline Canterbury Bulldogs & Sydney & $48 \%$ & $47 \%$ \\
\hline South Sydney & Sydney & $43 \%$ & $43 \%$ \\
\hline Manly Sea Eagles & Sydney & $43 \%$ & $42 \%$ \\
\hline Penrith Panthers & Sydney & $38 \%$ & $35 \%$ \\
\hline Sydney Roosters & Sydney & $36 \%$ & $35 \%$ \\
\hline Newcastle Knights & NNSW & $28 \%$ & $27 \%$ \\
\hline Cronulla Sharks & Sydney & $17 \%$ & $16 \%$ \\
\hline
\end{tabular}

${ }^{a}$ Geelong is geographically located outside of metropolitan Melbourne, but is captured as a ratings catchment area within 'greater Melbourne'. 
Table 3

Local Commencement Time of Friday Night Football Broadcasts

\begin{tabular}{lccccc}
\hline \multirow{4}{*}{ League } & Sydney & Melbourne & Brisbane & Adelaide $^{\mathrm{a}}$ & Perth $^{\mathrm{b}}$ \\
\cline { 2 - 5 } AFL & $23: 28$ & $20: 20$ & $23: 28$ & $20: 16$ & $20: 23$ \\
NRL & $19: 30$ & $24: 07$ & $19: 30$ & $24: 05$ & $24: 05$ \\
\hline $\begin{array}{l}\text { Note. Sample consists of AFL }(n=37) \text { and NRL }(n=47) \text { fixtures commencing at approximately 7:30pm played } \\
\text { on East Coast Australia during 2010 and 2011. }{ }^{a} \text { Adelaide is .5 hours behind East Coast Australia. }{ }^{\circ} \text { Perth is 2 } \\
\text { hours behind East Coast Australia. }\end{array}$
\end{tabular}


Table 4

Subscription Television Coverage Rate and Cost by Club

\begin{tabular}{lcc}
\hline \multicolumn{1}{c}{ Club } & $\begin{array}{c}\text { No. Exclusive } \\
\text { Games }\end{array}$ & $\begin{array}{c}\text { Cost Per } \\
\text { Game }\end{array}$ \\
\hline Collingwood Magpies & 3.6 & $\$ 323.33$ \\
Carlton Blues & 6.6 & $\$ 176.36$ \\
Geelong Cats & 6.8 & $\$ 171.18$ \\
Essendon Bombers & 7.2 & $\$ 161.67$ \\
St Kilda Saints & 7.6 & $\$ 153.16$ \\
Hawthorn Hawks & 7.6 & $\$ 153.16$ \\
Western Bulldogs & 9.4 & $\$ 123.83$ \\
Melbourne Demons & 9.6 & $\$ 121.25$ \\
Richmond Tigers & 10.2 & $\$ 114.12$ \\
Wests Tigers & 11 & $\$ 105.82$ \\
St. George Illawarra & 11.4 & $\$ 102.11$ \\
Parramatta Eels & 11.6 & $\$ 100.34$ \\
North Melbourne Kangaroos & 12 & $\$ 97.00$ \\
Canterbury Bulldogs & 12.4 & $\$ 93.87$ \\
Manly Sea Eagles & 13.6 & $\$ 85.59$ \\
South Sydney Rabbitohs & 13.6 & $\$ 85.59$ \\
Penrith Panthers & 14.8 & $\$ 78.65$ \\
Sydney Roosters & 15.4 & $\$ 75.58$ \\
Newcastle Knights & 17.2 & $\$ 67.67$ \\
Cronulla Sharks & 20 & $\$ 58.20$ \\
\hline No. NRL
\end{tabular}

Note. NRL clubs are shown in boldface. Figures are per season. ${ }^{\text {a }}$ Pro-rata cost per game based on an average 2011 subscription cost of $A \$ 1,164$. 
Table 5

FTA Rights Fee Return on Investment by League

\begin{tabular}{llcc}
\hline \multicolumn{1}{c}{ Code } & Viewer Minutes & Rights Fee Paid & Viewer Minutes Per \$ \\
\hline AFL & $93,785,406,300$ & $\$ 465,000,000$ & 202 \\
NRL & $56,213,364,315$ & $\$ 189,166,667^{\mathrm{a}}$ & 297 \\
\hline
\end{tabular}

${ }^{\mathrm{a}} 80 \%$ pro-rata value, adjusted to reflect that the final year (2012) of the NRL broadcast agreement fell outside the study period. 


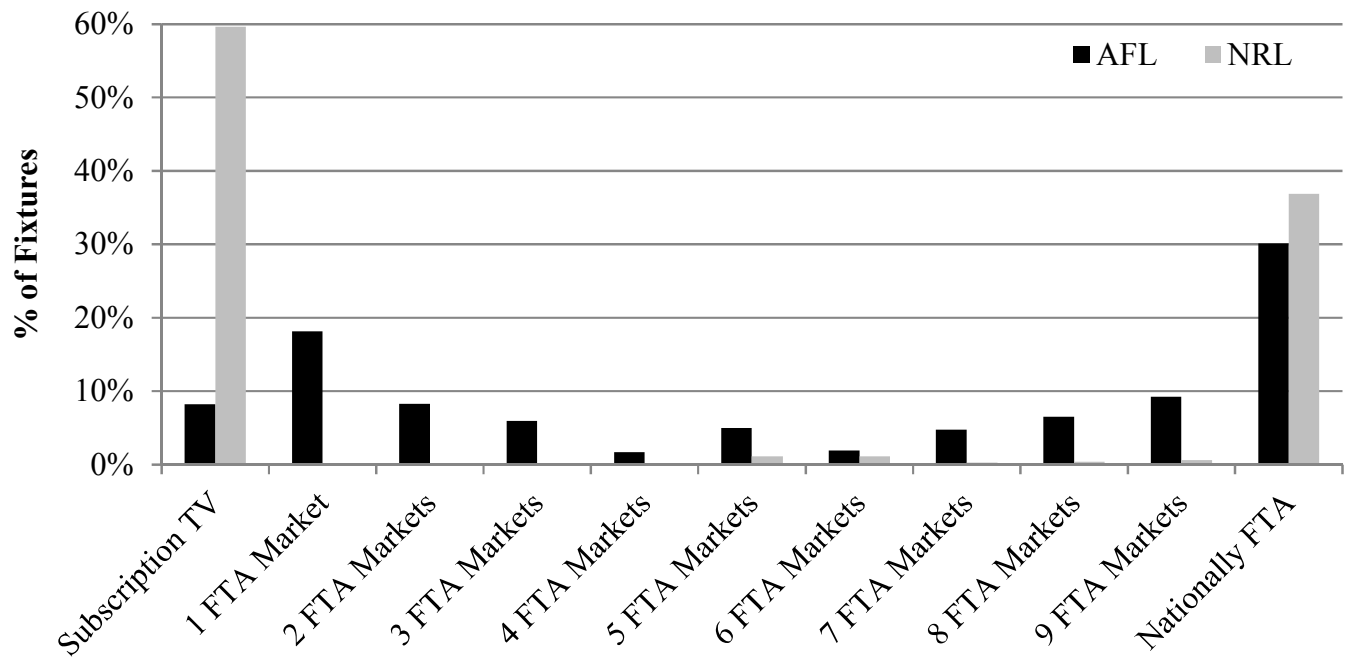

Figure 1. Distribution of AFL and NRL broadcasts between FTA and subscription television. Includes all regular season and finals fixtures contested between 2007 and 2011. 


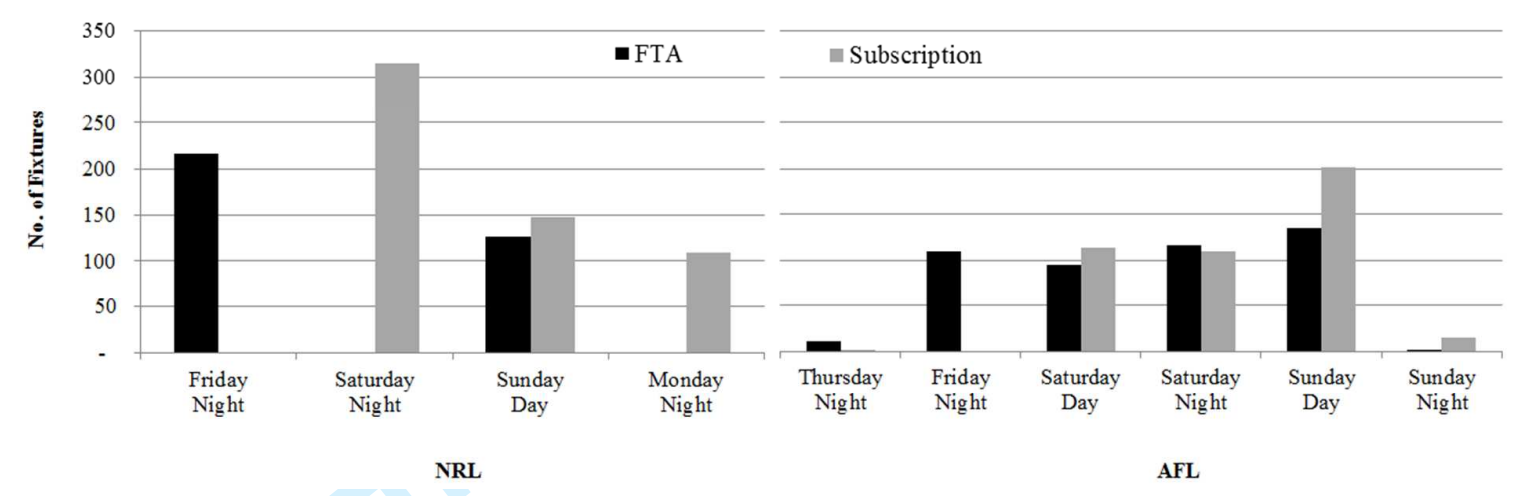

Figure 2. Comparison of Fixture Distributions by Day, Broadcaster and League. Based on all regular season fixtures contested between 2007 and 2011. 